\title{
Hydrographical Studies of Waters Adjacent to Nuclear Power Plants I and II in Northern Taiwan
}

\author{
Tien-Hsi Fang \\ Associate Professor, Department of Oceanography, National Taiwan Ocean University, Keelung, Taiwan 202., \\ thfang@mail.ntou.edu.tw \\ Jing-Fang Chen \\ Research Assistant, Department of Oceanography, National Taiwan Ocean University, Keelung, Taiwan 202. \\ Yueh-Yuan Tu \\ Director, Department of Industrial Safety and Environmental Protection, Taiwan Power Company, Taipei, Taiwan $100 .$. \\ Jiang-Shiou Hwang \\ Professor, Institute of Marine Biology, National Taiwan Ocean University, Keelung, Taiwan 202. \\ Wen-Tseng Lo \\ Associate Professor, Department of Marine Resources, National Sun Yat-Sen University, Kaohsiung, Taiwan 804.
}

Follow this and additional works at: https://jmstt.ntou.edu.tw/journal

Part of the Terrestrial and Aquatic Ecology Commons

\section{Recommended Citation}

Fang, Tien-Hsi; Chen, Jing-Fang; Tu, Yueh-Yuan; Hwang, Jiang-Shiou; and Lo, Wen-Tseng (2004) "Hydrographical Studies of Waters Adjacent to Nuclear Power Plants I and II in Northern Taiwan," Journal of Marine Science and Technology: Vol. 12: Iss. 5, Article 2.

DOI: $10.51400 / 2709-6998.2257$

Available at: https://jmstt.ntou.edu.tw/journal/vol12/iss5/2

This Research Article is brought to you for free and open access by Journal of Marine Science and Technology. It has been accepted for inclusion in Journal of Marine Science and Technology by an authorized editor of Journal of Marine Science and Technology. 


\section{Hydrographical Studies of Waters Adjacent to Nuclear Power Plants I and II in Northern Taiwan}

\section{Acknowledgements}

Thanks are given to assistance of the captain and crew of the R/V Ocean Researcher II during sampling. This research was financially supported by the Taiwan Power Company. The authors are grateful to an anonymous referee for his constructive comments and suggestions which led to improvements to the manuscript. 


\title{
HYDROGRAPHICAL STUDIES OF WATERS ADJACENT TO NUCLEAR POWER PLANTS I AND II IN NORTHERN TAIWAN
}

\author{
Tien-Hsi Fang*, Jing-Fang Chen**, Yueh-Yuan $\mathrm{Tu}^{* * *}$, \\ Jiang-Shiou Hwang $* * * *$, and Wen-Tseng Lo L $^{* * * * *}$
}

\section{ABSTRACT}

From 2000 to 2003, water samples were seasonally collected from the coastal area near nuclear power plants (NPPs) I and II to assess the ecological impact of thermal effluent on the water quality. The water quality in the investigated area during the survey periods was as follows: $\mathrm{pH}, 7.87-8.40$; dissolved oxygen, 3.61-7.11 mL/L; chlorophyll $a, 0.07-1.9 \mu \mathrm{g} / \mathrm{L}$; nitrite, 0.02-7.42 $\mu \mathrm{M}$; nitrate, 0.3$15.4 \mu \mathrm{M}$; phosphate, $0.02-1.48 \mu \mathrm{M}$; and silicate, $0.84-46.82 \mu \mathrm{M}$. The concentrations of nutrients in the spring and winter seasons were relatively higher than those in the summer and fall seasons. The concentrations of chlorophyll $a$ showed the reverse distribution. Overall, the water quality in the study area completely followed the "A level" seawater standard of EPA regulation, suggesting that the coastal seawater adjacent to both NPPs was not significantly affected by the thermal effluent from both NPPs.

Data on phytoplankton, zooplankton and water quality were combined and analysed using the principal component analysis to identify the factors influencing the marine ecology in the study area. Results showed that the percentages of the first principal component and the first two principal components generally accounted for more than $50 \%$ and $75 \%$, respectively. This result suggested that the system of the study area was mainly affected by two unspecified parameters. It was also found that water temperature, chlorophyll $a$, phytoplankton and zooplankton almost were located in the same axis in the plot of the first two principal component loadings, which differed from the plot of nutrients. This finding implied that water temperature was probably a more important factor in influencing the biomass of phytoplankton and zooplankton than the nutrients in the study area.

Paper Submitted 10/29/04, Accepted 02/21/05. Author for Correspondence: Tien-Hsi Fang. E-mail: thfang@mail.ntou.edu.tw.

*Associate Professor, Department of Oceanography, National Taiwan Ocean University, Keelung, Taiwan 202.

**Research Assistant, Department of Oceanography, National Taiwan Ocean University, Keelung, Taiwan 202.

***Director, Department of Industrial Safety and Environmental Protection, Taiwan Power Company, Taipei, Taiwan 100.

*****Professor, Institute of Marine Biology, National Taiwan Ocean University, Keelung, Taiwan 202.

******Associate Professor, Department of Marine Resources, National Sun Yat-Sen University, Kaohsiung, Taiwan 804.
Power plants affect the environment in various ways, as do all industrial factories. For example, fire power plants emit air pollutants that affect local air quality and can contribute to worldwide problems such as acid rain and global warming. Nuclear power plants draw in large volumes of cooling water from the adjacent seawater, use it, and then discharge it back into seawater, to some degree, affecting local fish stocks or marine ecology. Due to a lack of natural power resources, Taiwan Power Company began construction of the First and Second Power Plants at Shi-Man and Gin-San, respectively, in northern Taiwan in the beginning of 1970 and operation was launched late 1970. Moreover, the Third Power Plant was constructed in 1985 at Nanwan, in southern Taiwan. When each nuclear power plant started operation, long-term research programs investigating its impact on biology, ecology, chemistry and hydrography sponsored by Atomic Energy Council in the early stage and later by Taiwan Power Company, were carried out $[9,10,11,12,13,19]$. The purpose of the research programs was to investigate how thermal effluents affected marine ecology.

Two famous disastrous events were recorded during a long-term environmental monitoring. One is that two incidents of the coral bleaching were reported in July 1987 and July 1988 in adjacent seawater of the Third nuclear power plant in southern Taiwan [6]. The other is that the skeletal deformities of Terapon jarbua and Liza macrolepis were observed in 1993 in the outlet area of thermal effluent of the Second Nuclean Power Plant in northern Taiwan [8]. Both catastrophic events were related to thermal discharge from nuclear power plants, which elevated the water temperature and caused the damage. More detailed information of both events can be found elsewhere [9].

Nutrients, light and physical factors ultimately control the primary productivity in aquatic environments. Nitrogen, phosphorus and silicon are the essential nutri- 
Table 1. The sampling time of the investigated periods

\begin{tabular}{ccccc}
\hline & 2000 & 2001 & 2002 & 2003 \\
\hline the first season (spring) & March, 15-16 & March, 30-31 & March, 5-6 & January, 10-11 \\
the second season (summer) & May, 13-14 & May, 9-10 & May, 1-2 & April, 1-2 \\
the third season (autumn) & August, 1-2 & August, 3-4 & July, 1-2 & July, 15-16 \\
the fourth season (winter) & November, 7-8 & October, 3-4 & November, 12-13 & December, 5-6 \\
\hline
\end{tabular}

ents for phytoplankton in marine environments. As a result, nutrients usually play the most important role in regulating the ecological change of marine environments. It has been found that the long-term or temporal variations of nutrients can affect the phytoplankton community and populations, and subsequently influence the marine ecology in coastal environments [7, 14, 20].

From 2000 to 2003, we have seasonally investigated the nutrients, dissolved oxygen, temperature and chlorophyll a of inshore seawater adjacent to the First and the Second Nuclear Power Plants in northern Taiwan. The purpose of this study was to assess how the thermal effluent affects the water quality and to provide such information to the other research programs to monitor the marine ecological changes around the nuclear power plants. However, previous studies have shown that the influence of thermal discharges probably was restricted within $500 \mathrm{~m}$ or a shorter distance from the outlet of the thermal discharge $[10,11]$. Some investigation stations in this study were exempted from the influence of thermal effluent. Thus, here we present the water quality in coastal seawater adjacent to the First and the Second Nuclear Power Plants. Discussions were also addressed to reveal the key parameter in influencing the marine ecological system.

\section{MATERIALS AND METHODS SAMPLING}

The sampling times and stations are shown in Table 1 and Fig. 1, respectively. There were seven survey lines. Each nuclear power plant had three survey lines in parallel. One was located in the inlet of cooling water and extended seaward to $5 \mathrm{~km}$ where was considered as the temperature background station, i.e., a place where was absolutely not interfered by thermal effluent. The other two lines were located in the outlet of thermal effluent and extended seaward to $3 \mathrm{~km}$. Another line, in the central area between the First and the Second nuclear power plants, extended seaward from the mouth of the Huang Chi River. The sampling stations in each survey line were approximately $0 \mathrm{~m}, 250 \mathrm{~m}, 500 \mathrm{~m}, 1,000 \mathrm{~m}$, $1,500 \mathrm{~m}, 2,000 \mathrm{~m}$ and $3,000 \mathrm{~m}$ away from the coast. There was an additional station, 5,000 $\mathrm{m}$ away from the coast, in survey line $\mathrm{C}$ and $\mathrm{F}$, respectively. The sam-

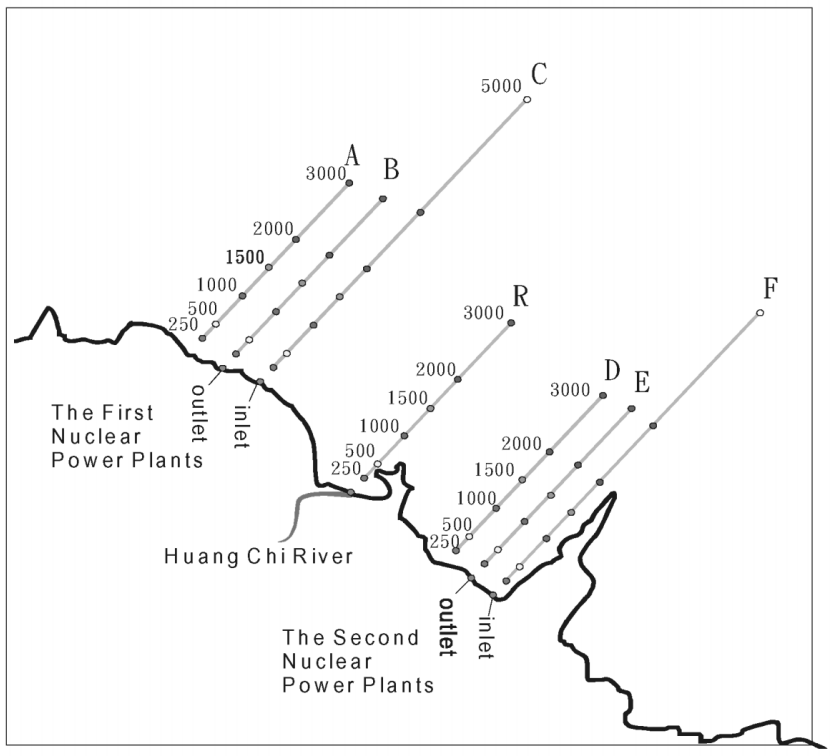

Fig.1. Map shows the sampling stations in coastal seawater adjacent to the First and the Second Nuclear Power Plant sites, in northern Taiwan.

pling depths were surface water $(0 \mathrm{~m}), 5 \mathrm{~m}, 10 \mathrm{~m}$ and 15 $\mathrm{m}$ at each station. Due to the shallowness of water, seawater at stations $0 \mathrm{~m}$ and $250 \mathrm{~m}$ was collected manually by Tain-Hei research vessel. The other sampling stations water samples were taken by R/V Ocean Research-II and were collected using Go-Flo bottles mounted on a Rosette sampling assembly. Temperature and salinity were also measured by a SeaBird CTD instrument. The nutrient samples were immediately filtered using the Whatman GF/F filter and were frozen on board after sampling. The Whatman GF/F filter was also frozen and was analyzed for the chlorophyll $a$. The dissolved oxygen samples were immediately added manganese chloride and alkaline iodide reagents on board. The measurements were carried out in laboratory on land. There were three groups of researchers working together to investigate the following three areas, namely the water quality, phytoplankton and zooplankton. The sampling station and distribution depth of phytoplankton and zooplankton are slightly 
different in the present study. The detailed descriptions of phytoplankton and zooplankton sampling scheme can be found in this volume.

The northern Taiwan is surrounded by the Taiwan Strait in the west, by the Kuroshio Water in the east and by East China Sea in the north. Due to the northern coast located at the continental shelf-break and at the route of the northeast monsoon, the Kuroshio Water occasionally intrudes into the northern shelf of Taiwan, forming a cold dome with upwelling subsurface water at the eastern edge of the shelf [15]. It is known that the Taiwan Strait Water is made up of three different water masses from the East China Sea, the South China Sea, and the Kuroshio Water. The flow pattern in the Taiwan Strait is dominated by the East Asian monsoon and generally has a northward flow [21]. Thus, the water masses in northern Taiwan are significantly influenced by the seasonal intrusion of the Kuroshio Water and by the northward flow of the Taiwan Strait Current.

\section{ANALYSIS}

The nutrients (dissolved phosphate, silicate, nitrite and nitrate) were measured using methods described in the Methods of Seawater Analysis [5]. Chlorophyll $a$ was determined by fluorometric method [18]. Direct spectrophotometry of total iodine was used to measure the dissolved oxygen [17]. The $\mathrm{pH}$ value of each sample was determined using a $\mathrm{pH}$ meter (Radiometer Copenhagen, model PHM 210).

For better assessments of the ecological system within the area influenced by the thermal discharge, a statistical method, the principal component analysis, was employed to analyze the data. The data obtained at stations 3,000 $\mathrm{m}$ and 5,000 $\mathrm{m}$ were excluded due to both a lack of phytoplankton and zooplankton data and the seawater not affected by the thermal effluent. The phytoplankton and zooplankton data were taken from annual report of the research program [11, 12, 13, 19]. The data of nutrients (phosphate, silicate, nitrate and nitrite), dissolved oxygen, chlorophyll $a$, temperature, phytoplankton and zooplankton were normalized to the mean value of the whole year data of each parameter prior to the analysis.

\section{RESULTS AND DISCUSSION}

The concentration ranges of the study parameters in the investigated areas from 2000 to 2003 are as follows: pH, 7.87-8.40; dissolved oxygen, 3.61-7.11 $\mathrm{mL} / \mathrm{L}$; chlorophyll $a, 0.07-1.9 \mu \mathrm{g} / \mathrm{L}$; nitrite, 0.02-7.42 $\mu \mathrm{M}$; nitrate, 0.3-15.4 $\mu \mathrm{M}$; phosphate, 0.02-1.48 $\mu \mathrm{M}$; and silicate, $0.84-46.82 \mu \mathrm{M}$. These values found in seawater adjacent to the First and the Second Nuclear
Power Plants and to the Hwang Hsi River in each year are listed in Table 2. The concentrations of nutrients, especially silicate, obtained at stations of the Hwang Hsi River line were generally higher than those at stations of the nuclear power plants lines. This finding is not surprising because riverine input is a major source of nutrients in coastal environments. However, the point source, such as marine dumping, ocean outfall, groundwater intrusion and antifouling added to the cooling water effluent, could significantly elevate the concentration and alternate the composition of chemical constituents in coastal waters [2].

A decrease in the concentrations of nutrients in seawater was shown seawards due to seawater dilution effect. However, such phenomenon was not seen in the study area $[11,12,13,19]$. The reason for this is probably that the amount of river discharge from the Huang Chi River was relatively minor such that its influence could not reach to the coastal area near the First and the Second Nuclear Power Plants. The water quality of "A level" seawater of Taiwan EPA regulation was as follow: $\mathrm{pH}, 7.5-8.5$; dissolved oxygen, $\geq 5 \mathrm{mg} / \mathrm{L}$ (ca. $3 \mathrm{ml} / \mathrm{L})$; ammonia, <0.3 mg/L $(21.4 \mu \mathrm{M})$; and total dissolved phosphorus $<0.05 \mathrm{mg} / \mathrm{L}(1.6 \mu \mathrm{M})$. There were no nitrite, nitrate and silicate regulation. It was well documented that ammonia will be oxidized to nitrite and finally to nitrate under oxidizing environment [16]. Although, ammonia was not determined in the present study, the concentrations of dissolved oxygen in the study area always exceeded 4-5 mL/L, approaching to saturation, during the investigation period (see Figs. 2-4). Theoretically, the concentration of ammonia in oxidizing seawater should be less than 0.5 $\mu \mathrm{M}$ [16]. The concentration of dissolved inorganic phosphorus (phosphate) in coastal seawater usually accounted for more than $80 \%$ of total dissolved phosphorus $[3,4]$. The concentration of phosphate in seawater adjacent to the First and the Second Nuclean Power Plants rarely exceeded $1.0 \mu \mathrm{M}$. Thus, the concentration of total dissolved phosphorus in the study area should not surpass the EPA regulation (total dissolved $P>1.6$ $\mu \mathrm{M})$. Overall, the water quality in the study area completely follow the "A level" seawater standard of EPA regulation, suggesting that the inshore seawater adjacent to nuclear power plants was not contaminated by nutrient elements.

In order to examine the inter-seasonal variability of $\mathrm{pH}$, dissolved oxygen, temperature and nutrients in the areas surveyed, the ranges of seasonal concentration of these parameters under study are plotted in Figures 24 , which indicates that the concentrations of nutrients in the summer and fall surveys were generally lower than the spring and winter surveys. In contrast, the result of chlorophyll $a$ showed the opposite trend. This result is 
in agreement with the report of Chang et al. [1] which showed that the concentrations of chlorophyll $a$ in seawater of northern Taiwan in the autumn and fall seasons were higher than those in the spring and winter seasons. The fact that phytoplankton blooms consume the nutrients caused the concentrations of chlorophyll $a$ and nutrients exhibited the reverse distribution.

Because there were lack of phytoplankton and zooplankton data at stations $3,000 \mathrm{~m}$ and $5,000 \mathrm{~m}$ and the CTD results showed that the influence of thermal discharges of the First and the Second Nuclear Power Plants was probably restricted within 1,000-2,000 m from the thermal discharge outlet [11,12]. The results of principal component analysis, based on data obtained at stations within $2,000 \mathrm{~m}$, are shown in Table 3 and Figures 5-6. Table 3 shows that the percentage of the first principal component found in the First and the Second Nuclear Power Plants area was greater than $50 \%$, except in 2002 when the percentage reduced to 35 $40 \%$. The percentage of the second principal component ranged from $15 \%$ to $28 \%$. This result suggests that one of the parameters under study had significant influence on the ecological system.

The plots of the first two principal component loading, showing the relationship between phosphate, silicate, nitrite, nitrate, dissolved oxygen, temperature, chlorophyll $a$, phytoplankton and zooplankton, were depicted in Figures 5 and 6 . Surprisingly, temperature, chlorophyll $a$, phytoplankton and zooplankton were almost located in the same axis and differed from the nutrients. Phosphate, silicate, nitrite and nitrate can be grouped together in the other axis. These results imply that the influence of water temperature on the ecology of phytoplankton and zooplankton in the area under study were more important than that of the nutrients. The reason for this may probably be that the concentrations of nutrients were sufficient to supply the phytoplankton growth in the whole year and were not the limiting factor of the primary productivity. In contrast, the seawater temperature variations in the study area were significant. The average temperature of seawater was generally less than $25^{\circ} \mathrm{C}$ or even colder in the winter and spring seasons but exceeded $25^{\circ} \mathrm{C}$ or warmer in the summer and autumn seasons. Chang et al. [1] observed the seasonal variation of seawater temperature and phytoplankton biomass in coastal seawater outside of the Taiwan Ocean University, Keelung, in their biweekly sampling. Their results showed that water temperature at the study site varied between 17 and $30^{\circ} \mathrm{C}$ in 1994. Both chlorophyll $a$ concentration and Synechococcus abundance were low in the winter and started to increase when surface water became warmer than $25^{\circ} \mathrm{C}$. Their result also confirmed that seawater temperature was an important factor in controlling the phytoplank- 

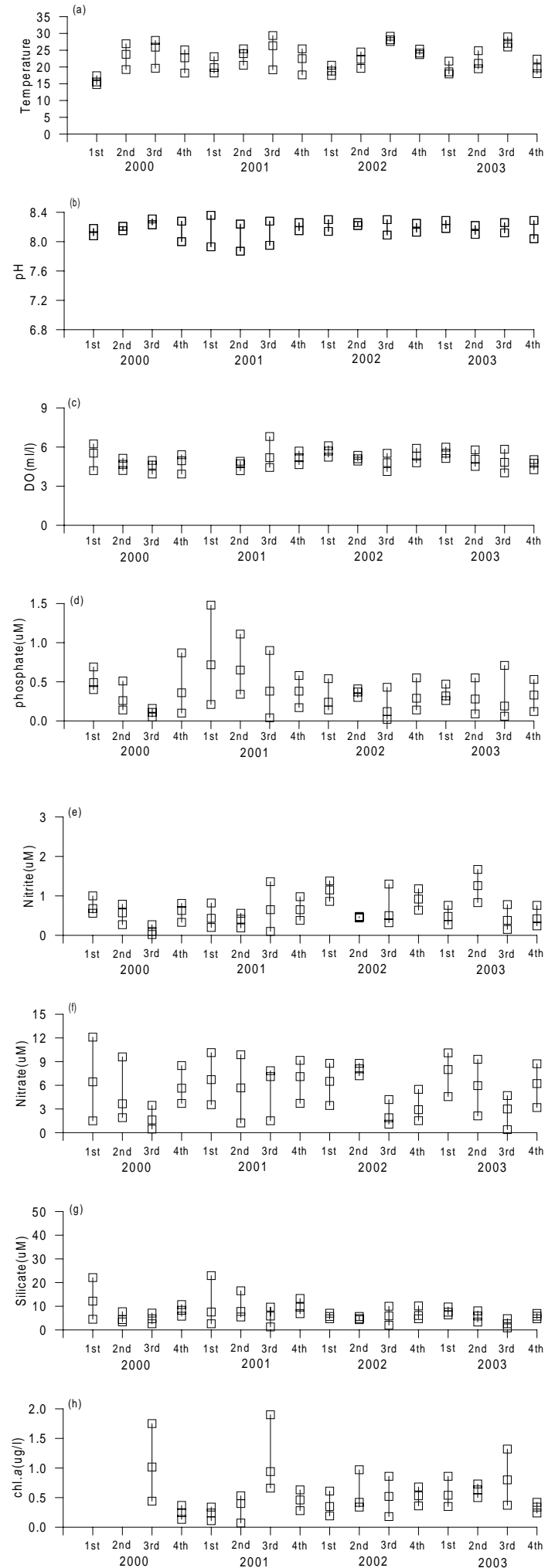

Fig. 2. The concentration ranges of water quality: (a) temperature, (b) pH, (c) DO, (d) phosphate, (e) nitrite, (f) nitrate, (g) silicate, and (h) chlorophyll $a$ in seawater adjacent to the First Nuclear Power Plant site in each season from 2000 to 2003. The central square represents the mean value.
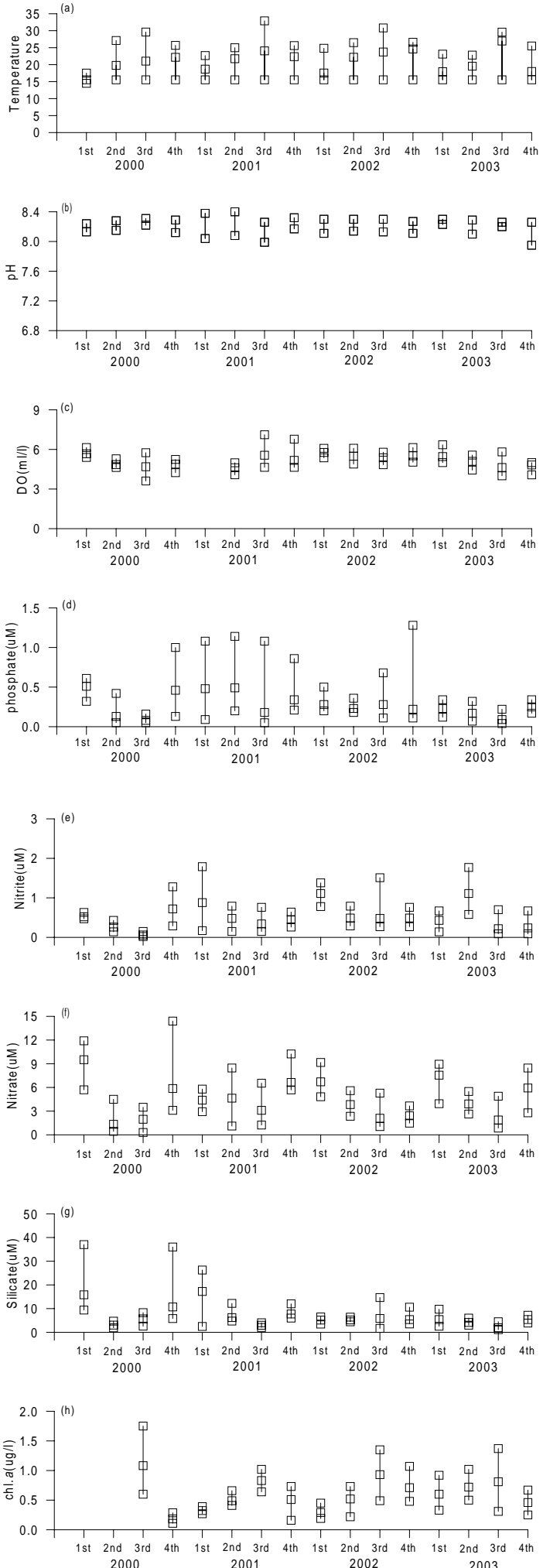

Fig. 3. The concentration ranges of water quality: (a) temperature, (b) pH, (c) DO, (d) phosphate, (e) nitrite, (f) nitrate, (g) silicate, and (h) chlorophyll $a$ in seawater adjacent to the Second Nuclear Power Plant site in each season from 2000 to 2003. The central square represents the mean value. 
Table 3. The percentages of the first and the second principal component among the study parameters found in the First and the Second Nuclear Power Plant (NPP) coastal seawater in each year

\begin{tabular}{lcccccccc}
\hline Year & \multicolumn{2}{c}{2000} & \multicolumn{2}{c}{2001} & \multicolumn{2}{c}{2002} & \multicolumn{2}{c}{2003} \\
\hline Location & 1st NPP & 2nd NPP & 1st NPP & 2nd NPP & 1st NPP & 2nd NPP & 1st NPP & 2nd NPP \\
$\begin{array}{c}\text { The first principal } \\
\text { component (\%) }\end{array}$ & 62.1 & 53.3 & 49.4 & 59.2 & 35.7 & 41.5 & 54.5 & 51.7 \\
$\begin{array}{c}\text { The second principal } \\
\quad \text { component (\%) }\end{array}$ & 21.1 & 15.8 & 28.5 & 18.1 & 21.1 & 22.6 & 15.6 & 18.9 \\
$\begin{array}{c}\text { The first plus the second } \\
\text { principal component (\%) }\end{array}$ & 83.2 & 69.1 & 77.8 & 77.3 & 56.8 & 64.1 & 70.1 & 70.6 \\
\hline
\end{tabular}
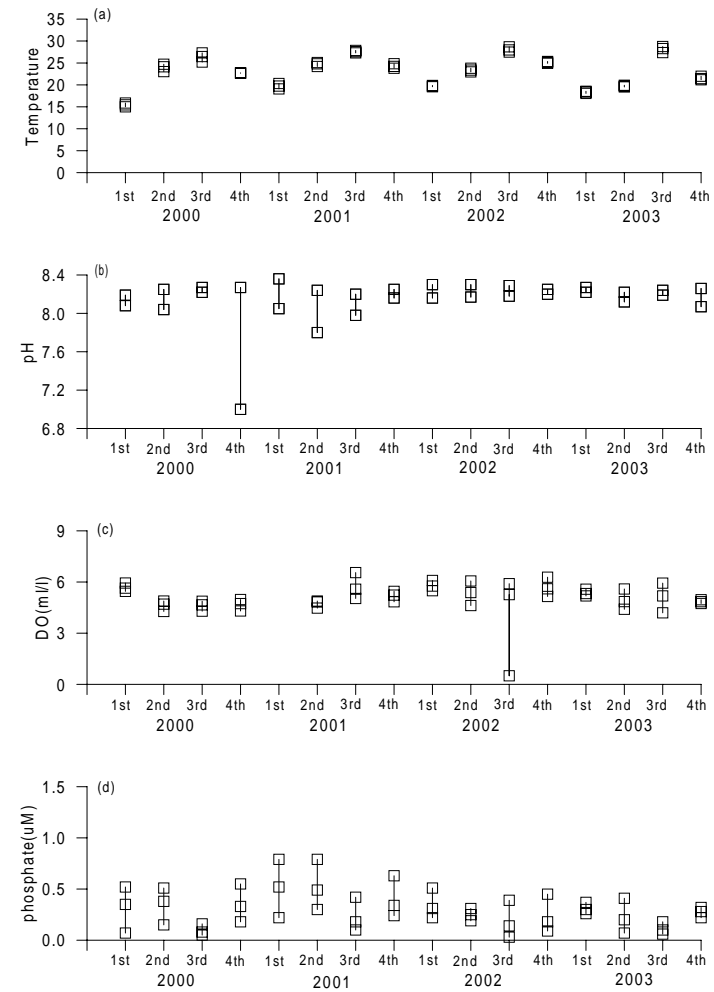
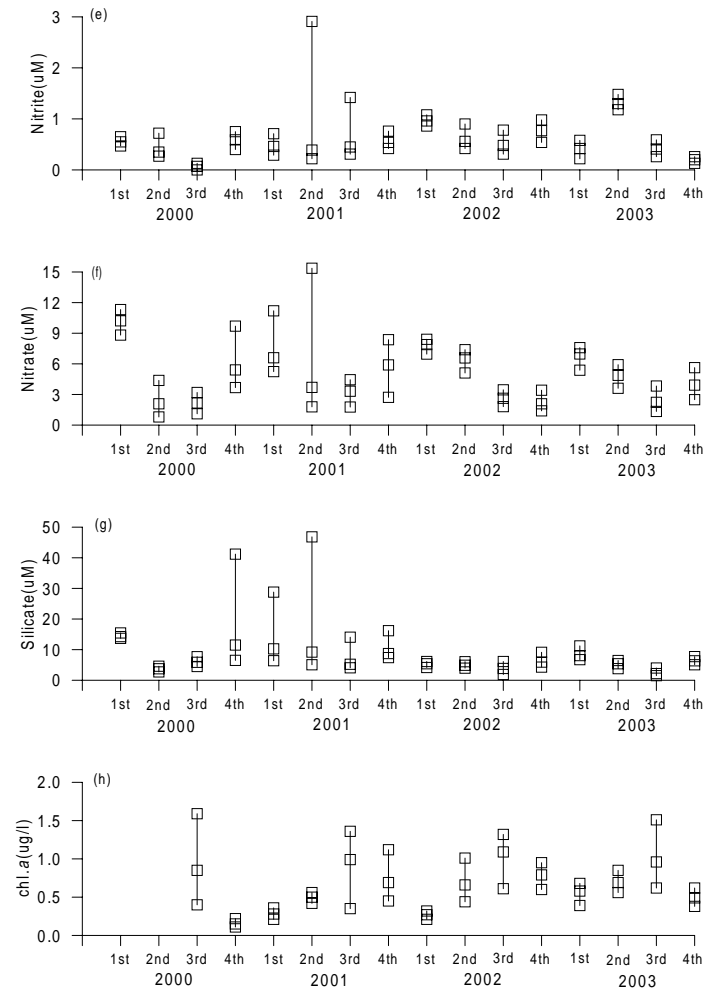

Fig. 4. The concentration ranges of water quality (a) temperature, (b) pH, (c) DO, (d) phosphate, (e) nitrite, (f) nitrate, (g) silicate, and (h) chlorophyll $a$ in seawater adjacent to the Huang Chi River in each season from 2000 to 2003. The central square represents the mean value.

ton biomass in seawater in northern Taiwan, which was the same as what we had observed.

\section{CONCLUSION}

This study presents the results of seasonal investigation, from 2000 to 2003, of water quality in coastal area adjacent to the First and the Second Nuclear Power Plants in northern Taiwan. The water quality in the study area completely followed the "A level" seawater standard of EPA regulation, suggesting that the coastal seawater was not contaminated by nutrient elements. The impact of the thermal effluent of the nuclear power plants on water quality was not apparent. The concentrations of nutrients (phosphate, silicate, nitrite and nitrate) in the area under study showed seasonal variations: higher concentrations in the summer and fall seasons and lower concentrations in the spring and winter seasons. In contrast, the concentration of chlorophyll $a$ exhibited the reverse distribution. The results of statistical analyses highlighted that seawater temperature probably played a key role in influencing the ecology of phytoplankton and zooplankton in seawater adjacent to the First and the Second Nuclear 

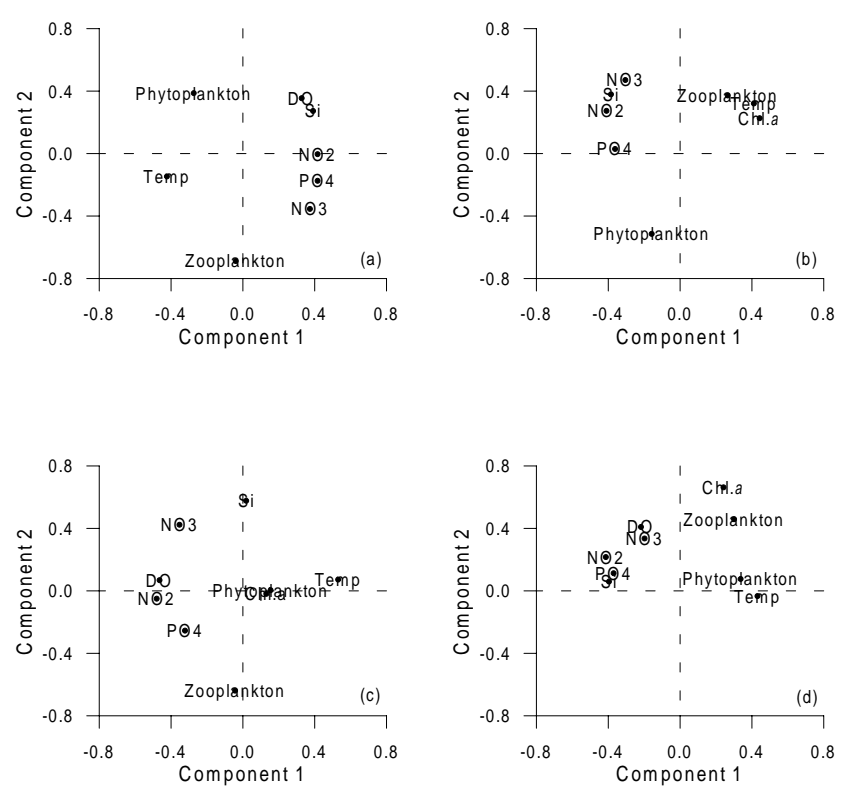

Fig. 5. Plot of the first two principal component loadings showing the relationship between temperature (Temp), dissolved oxygen (DO), phosphate $\left(\mathrm{PO}_{4}\right)$, nitrite $\left(\mathrm{NO}_{2}\right)$, nitrate $\left(\mathrm{NO}_{3}\right)$, silicate (Si), chlorophyll $a$, phytoplankton, and zooplankton in seawater adjacent to the First Nuclear Power Plant site during (a) 2000, (b) 2001, (c) 2002, and (d) 2003.

Power Plants. The nutrients were sufficient to supply the phytoplankton growth throughout the whole year and were not limiting factors of the primary productivity.

\section{ACKNOWLEDGEMENTS}

Thanks are given to assistance of the captain and crew of the R/V Ocean Researcher II during sampling. This research was financially supported by the Taiwan Power Company. The authors are grateful to an anonymous referee for his constructive comments and suggestions which led to improvements to the manuscript.

\section{REFERENCES}

1. Chang, J., Chung, C.C., and Gong, G.C., "Influences of Cyclones on Chlorophyll a Concentration and Synechococcus Abundance in a Subtrophical Western Pacific Coastal Ecosystem," Mar. Ecol. Prog. Ser., Vol. 140, pp. 199-205 (1996).

2. Clark, R.B., Marine Pollution, $5^{\text {th }}$ Edition, Oxford University Press, Oxford (2001).

3. Fang, T.H., "Partitioning and Behaviour of Different Forms of Phosphorus in the Tansui Estuary and One of Its Tributaries, Northern Taiwan," Estuar., Coast. Shelf Sci., Vol. 50, pp. 689-701 (2000).

4. Fang, T.H., "Phosphorus Speciation and Budget of the
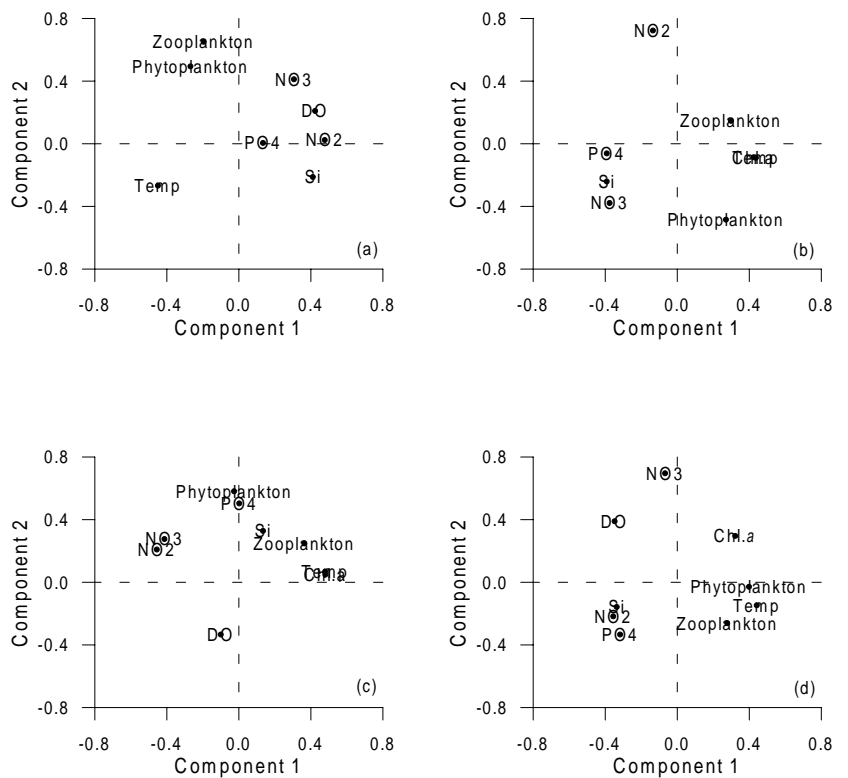

Fig. 6. Plot of the first two principal component loadings showing the relationship between temperature (Temp), dissolved oxygen (DO), phosphate $\left(\mathrm{PO}_{4}\right)$, nitrite $\left(\mathrm{NO}_{2}\right)$, nitrate $\left(\mathrm{NO}_{3}\right)$, silicate (Si), chlorophyll $a$, phytoplankton, and zooplankton in seawater adjacent to the Second Nuclear Power Plant site during (a) 2000, (b) 2001, (c) 2002, and (d) 2003.

East China Sea," Cont. Shelf Res., Vol. 24, pp. 12851299 (2004).

5. Hansen, H.P. and Koroleff, F., "Determination of Nutrients," Methods of Seawater Analysis, Grasshoff, K., Kremling, K., and Ehrhardt, M. (Eds.), Wiley-VCH, Weinheim, pp. 159-223 (1999).

6. Huang, C.C., Hung, T.C., and Fan, K.L., "Nonbiological Factors Associated with Coral bleaching in Shallow Water Near the Outlet of the Third Nuclear Power Plant, Southern Taiwan," UNEP Reg. Seas Rep. Stud., Vol. 147, pp. 205-224, Taipei, Taiwan (1992).

7. Humborg, C., Ittekkot, V., Cociasu, A., and Bodungen, B.V., "Effect of Donube River Dam on Black Sea Biochemistry and Ecosystem Structure," Nature, Vol. 386, pp. 385-388 (1997).

8. Hung, T.C., Chiang, Y.M., Tan, T.H., Shao, K.T., Huang, C.C., Chen, J.C., Chu, T.C., and Fan, K.L., "An Ecological Survey on the Waters Adjacent to the Northern Taiwan Nuclear Power Plant Sites Including Yenliao Coastal Area," SCOPE/Academic Sinica, Vol. 90, pp. 195, Taipei, Taiwan (1994).

9. Hung, T.C., Huang, C.C., and Shao, K.T., "Ecological Survey of Coastal Water Adjacent to Nuclear Power Plants in Taiwan," Chem Ecol., Vol. 15, pp. 129-142 (1998).

10. Hwang, J.S., Cheng, I.J., Shao, K.T., Hu, J.H., Huh, C. A., Fang, T.H., and Lo, W.T., "The Ecological Survey of 
Coastal Seawater Adjacent to the Nuclear Power Plants in Northern Taiwan: 2000 Annual Report," National Taiwan Ocean University, Keelung, Taiwan (2001).

11. Hwang, J.S., Cheng, I.J., Shao, K.T., Hu, J.H., Huh, C. A., Fang, T.H., and Lo, W.T., "The Ecological Survey of Coastal Seawater Adjacent to the Nuclear Power Plants in Northern Taiwan: 2001 Annual Report," National Taiwan Ocean University, Keelung, Taiwan (2002).

12. Hwang, J.S., Cheng, I.J., Shao, K.T., Hu, J.H., Huh, C.A., Fang, T.H., and Lo, W.T., "The Ecological Survey of Coastal Seawater Adjacent to the Nuclear Power Plants in Northern Taiwan: 2002 Annual Report," National Taiwan Ocean University, Keelung, Taiwan (2003).

13. Hwang, J.S., Cheng, I.J., Shao, K.T., Hu, J.H., Huh, C.A., Fang, T.H., and Lo, W.T., "The Ecological Survey of Coastal Seawater Adjacent to the Nuclear Power Plants in Northern Taiwan: 2003 Annual Report," National Taiwan Ocean University, Keelung, Taiwan (2004).

14. Lane, R.R., Day, J.W., Justic, D., Reyes, E., Marx, B., Day, J.N., and Hyfield, E., "Changes in Stoichiometeric Si, N and P Ratios of Mississippi River Water Diverted Through Coastal Wetlands to the Guulf of Mexico," Estuar. Coast. Shelf Sci., Vol. 60, pp. 1-10 (2004).

15. Liu, K.K., Gong, G.C., Shyu, C.Z., Pai, S.C., Wei, C.L., and Chao, S.Y., "Response of Kuroshio Upwelling to the
Inset of the Northeast Monsoon in the Sea North of Taiwan: Observations and a Numerical Simulation," J. Geophys. Res., Vol. 97, pp. 12511-12526 (1992).

16. Millero, F., Chemical Oceanography, $2^{\text {nd }}$ Edition, CRC Press, Boca Raton (1996).

17. Pai, S.C., Gong, G.C., and Liu, K.K., "Determination of Dissolved Oxygen in Seawater by Direct Spectrophotometry of Total Iodine," Mar. Chem., Vol. 41, pp. 343351 (1993).

18. Parson, T.R., Maita, Y., and Lalli, C., A Manual of Chemical and Biological Methods for Seawater Analysis, Pergamon Press, Oxford (1984).

19. Su, J.C., Hung, T.C., Chiang, Y.M., Tan, T.H., Lo, C.T., Chang, K.H., Lee, C.T., and Chang, T.H., An Ecological Survey on the Waters Adjacent to the Northern Taiwan Nuclear Power Plant Sites, Background Studies (July 1974-June 1979), Spec. Publ. Atom. Ener. Coun. Taipei, Taiwan (1979).

20. Turner, R.E. and Rabalais, N.N., "Coastal Eutrophication Near the Mississippi river Delta," Nature, Vol. 368, pp. 619-621 (1994).

21. Wang, J. and Chern, C.S., "On the Kuroshio Branch in the Taiwan Strait During Wintertime," Prog. Oceanogr., Vol. 21, pp. 469-491 (1988). 